\title{
Rural-urban difference in blood pressure measurement frequency among elderly with hypertension: a cross-sectional study in Shandong, China
}

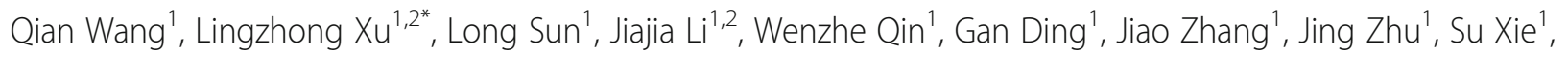
Zihang $\mathrm{Yu}^{1}$ and Chengchao Zhou ${ }^{1,2}$

\begin{abstract}
Background: Blood pressure measurement is the first step in preventing and controlling hypertension. The objective of this study is to examine the rural-urban difference towards blood pressure measurement among elderly with hypertension.
\end{abstract}

Methods: A total of 2007 elderly (65+) were selected from the fifth Health Service Survey of Shandong Province in 2013. A standardized questionnaire was used to investigate the demographic characters, socioeconomic status, selfrated health, and blood pressure related index. Three logistic regression models were used to examine the difference in blood pressure measurement between rural and urban elderly. Unadjusted and adjusted logistic regression models were used to explore the associated factors of blood pressure measurement in both rural areas and urban areas.

Results: The prevalence of weekly blood pressure measurement in urban elderly was higher than that in rural elderly (63.9\% vs 34.3\%). The rural elderly had an odds ratio (OR) for weekly blood pressure measurement of 0.467 $(95 \% \mathrm{Cl}=0.380-0.575)$ compared with urban elderly. Binary logistic regression analysis showed that medication frequency and accepting health care professionals' guidance were common associated factors of blood pressure measurement among both rural and urban elderly; personal income was unique associated factor of blood pressure measurement among rural elderly; marital status, education level, self-rated health, and blood pressure level currently were unique associated factors of blood pressure measurement among urban elderly.

Conclusions: There is a big difference in blood pressure measurement between rural and urban elderly. Interventions targeting identified at-risk subgroups, especially for those rural elderly, should be made to reduce such a gap.

Keywords: Blood pressure measurement, Elderly, Rural-urban difference, China

\footnotetext{
* Correspondence: Izxu@sdu.edu.cn

${ }^{1}$ School of Public Health, Shandong University, Jinan 250012, China

${ }^{2}$ Collaborative Innovation Center of Social Risks Governance in Health, School

of Public health, Fudan University, Shanghai 200032, China
}

(c) The Author(s). 2018 Open Access This article is distributed under the terms of the Creative Commons Attribution 4.0 International License (http://creativecommons.org/licenses/by/4.0/), which permits unrestricted use, distribution, and reproduction in any medium, provided you give appropriate credit to the original author(s) and the source, provide a link to the Creative Commons license, and indicate if changes were made. The Creative Commons Public Domain Dedication waiver (http://creativecommons.org/publicdomain/zero/1.0/) applies to the data made available in this article, unless otherwise stated. 


\section{Background}

Hypertension is one of the most common risk factors for cardiovascular disease [1]. It already affects more than one billion people worldwide, leading to heart attacks and strokes [2]. Complications from hypertension account for 9.4 million deaths worldwide every year [3]. In China, about 2.1 million total cardiovascular deaths and 1.2 million premature cardiovascular deaths were attributable to hypertension every year [4].

A population-based screening project in 2017 that enrolled around 1.7 million adults from all 31 provinces in mainland China showed that $44.7 \%$ of the sample had hypertension [5].

Fortunately, hypertension can be prevented. Detecting high blood pressure is the first step in preventing and controlling it. Acting Director of the WHO Department for Management of Noncommunicable Diseases, Dr. Shanthi Mendis, said that "Early detecting of high blood pressure and lowering heart attack and stroke risk is clearly far less expensive for individuals and governments than heart surgery, stroke care, dialysis, and other interventions that may be needed later if high blood pressure is left unchecked and uncontrolled." WHO called on all adults around the world to measure their blood pressure to make people know the blood pressure level and take steps to control it on World Health Day 2013 [6]. Some studies have already proved that blood pressure (BP) measurement can significantly control the level of $\mathrm{BP}$, reduce incidence of adverse reactions, decrease the cost of hypertension treatment, and improve adherence to antihypertensive medication [7-11].

Unfortunately, the rate of BP measurement is not optimistic. There are many studies about the current situation of BP measurement. An investigation in Italy found that about $56.9 \%$ of hypertensive patients performed one or more BP measurement weekly [12]. In China, about $42.8 \%$ hypertensive patients measured BP weekly in Beijing, 36.9\% in Chengdu and $46.3 \%$ in Guangzhou [13-15]. The low rate of BP measurement needs to be solved quickly.

Since our population is aging, and hypertension affects most elderly people, these individuals are more likely to have organ damage or clinical cardiovascular disease (CVD). In China, the percentage of 65 and older people is $10.1 \%$ in 2015 , and it predict to reach $26.8 \%$ in 2050 [16]. The prevalence of hypertension in China increases with the age [17]. However, the rate of BP measurement among elderly was not optimistic now [13].

In the present study, we focused on the elderly with hypertension in Shandong Province. Shandong Province has the second largest population in China, and the percentage of its elderly population $(65+)$ has reached $13.15 \%$ by 2016 . What is more, the prevalence of hypertension in Shandong Province was high. In 2013 in
Shandong Province, the prevalence of hypertension is $24.33 \%$, higher than most of other provinces [18]. Therefore, Shandong becomes an ideal place to examine the BP measurement among elderly with hypertension and its related factors. Although there have been many studies focused on the associated factors of BP measurement, none of them have explored the differences between rural and urban areas. Our study aims to explore the ruralurban difference of BP measurement among elderly with hypertension and its separate associated factors.

\section{Methods}

\section{Data and study population}

Data were drawn from the fifth Health Service Survey of Shandong Province, which was part of China's fifth National Health Service Survey (NHSS), conducted in 2013. NHSS is a national representative survey organized and directed by the Ministry of Health of China every 5 years.

To achieve representation of the whole population, a four-stage, stratified, random sampling method was adopted in both years. In the first stage, 20 counties (districts) were randomly selected in Shandong Province. The second stage sampled townships: 100 townships were selected in sampled counties or districts. In the third stage, 200 villages (communities) were selected in sampled townships. In the fourth stage, 12,000 households were identified. For each household, a face-to-face interview was conducted using a structured household questionnaire which was developed by the Center for Health Statistics and Information of the Ministry of Health of China [19-21].

Among a total of 33,070 respondents, we included hypertensive patients aged $\geq 65$ years old $(n=2104)$. After data cleaning (i.e., excluding participants with key variables missing or with logic error answers), a study sample of 2007 hypertensive patients were adopted for analysis.

\section{Dependent variables}

BP measurement frequency was derived from a question "When was the last time you measured your BP?" They could choose one of the five responses ("within a week" "within a month" "within three months" "within six months" "more than six months"). According to Chinese guidelines for the management of hypertension in 2010, patients with controlled BP should measure BP at least once a week [22]. Therefore, we defined measurement frequency as a binary variable: we assigned patients a value of 1 if they have measured BP within 1 week; and for patients who measured BP longer than 1 week, a value of 0 was assigned.

\section{Independent variables Covariates}

Age, gender, and marital status were used as demographic characteristics. Age was categorized as 65 to 69, 
70 to 74,74 to 79 , and 80 years or more. Marital status was classified as married and single, latter one includes unmarried, divorced, and widowed. Socioeconomic status was measured separately via education level and personal income level. Education level was classified into three categories: no formal education, primary education, secondary, or above. Personal income was calculated by household income and household size, and classified into 5 levels: 0 to 2500, 2500 5000, 5000 10,000, 10,000 20,000, $\geq 20,000$ Yuan, RMB per year. Self-rated health score was categorized as bad, moderate, and good.

\section{BP-related variables}

BP-related variables included medication frequency, blood pressure level currently, and accepting health care professionals' guidance. Medication frequency was classified as on time, occasional, and never. BP level currently was categorized as normal and others (abnormal and unsure). The entry "accepting health care professionals' guidance" was defined by an affirmative response to the question "In recent three months, have you ever been guided by health care professionals in the prevention and treatment of hypertension?"

\section{Statistical analysis}

Data analyses were conducted using SPSS 24.0. Descriptive statistics, including frequency and percentage, were used to describe the social-demographic and BP management characteristics of the patients. Chi-square tests were used to explore the relationships between age, gender, marital status, education level, personal income, self-rated health, BP-related variables, and measurement frequency.

Binary logistic regression models were used to examine the rural-urban difference of measurement frequency. Model 1: univariate model. Model 2: binary logistic regression model, adjusted for demographic characteristics (age, gender, marital status), socioeconomic status (education level and personal income), and self-rated health. Model 3 : in addition to the factors in model 2, BP-related variables (medication frequency, BP level currently, accepting health care professionals' guidance) were included. Univariate models and adjusted binary logistic regression models were used to explore the risk factors of measurement frequency among both rural and urban elderly. Because NHSS has a complex sampling design, sampling weights were considered in the logistic regression analyses. A $P$ value of less than 0.05 was considered statistically significant for the test.

\section{Results}

General characteristic of the participants

Among these 2007 participants, 1107 (55.2\%) were rural elderly, 900(44.8\%) were urban elderly. The mean age was 72.74 $(\mathrm{SD}=6.15)$, and most of the participants were currently married $(72.8 \%)$. More than one-third (35\%) of the patients had no formal education, and most of them were unemployed (81.1\%). As for BP management characteristics, most of the patients took medicine on time (79.1\%). More than half of the patients had normal BP currently (58.5\%). And approximately two-thirds (69.1\%) of them had accepted health care professionals' guidance. Since weekly BP measurement is more clinically useful, the presentation of results focused on the weekly categories. There was statistically significant difference in the frequency of BP measurement between rural group and urban group. Besides, age, gender, marital status, education level, personal income, self-rated health, medication frequency, BP level currently, and accepting health care professionals' guidance were also significantly different between rural elderly and urban elderly (Table 1 ).

The result showed that 955(47.6\%) elderly patients measured BP weekly and 1052 (52.42\%) did not. Among these $955(47.6 \%)$ patients who measured BP weekly, 380 (34.3\%) were rural elderly and $575(63.9 \%)$ were urban elderly (Table 2 ).

\section{Rural-urban difference in blood pressure measurement in different logistic regression models}

The results of logistic regression models for the association between rural-urban group and BP measurement are presented in Table 3. After adjusting for covariates, model 3 showed that rural elderly did BP measurement less than the urban elderly, the OR was 0.467 (95\% CI = 0.380-0.575). All of the three models indicated the rural-urban differences in BP measurement frequency (Table 3).

\section{Risk factors of blood pressure measurement among rural elderly}

The results of logistic regression models showed that personal income was significantly associated with BP measurement frequency among rural elderly. Moreover, elderly hypertensive patients who took medicine occasionally $(\mathrm{OR}=0.539,95 \% \mathrm{CI}=0.404-0.718) \quad$ or never took medicine $(\mathrm{OR}=0.349,95 \% \mathrm{CI}=0.201-0.604)$ were less likely to practice $\mathrm{BP}$ measurement compared to those on time ones. Patients who had not accepted health care professionals' guidance recently were less likely to engage in timely $\mathrm{BP}$ measurement $(\mathrm{OR}=0.519$, 95\% CI = 0.400-0.674) (Table 4).

\section{Risk factors of blood pressure measurement among urban elderly}

The results indicated that those married elderly were associated with more frequent $\mathrm{BP}$ measurement than those single ones $(\mathrm{OR}=1.367,95 \% \mathrm{CI}=1.017-1.837)$. Education levels were significantly associated with the frequency of 
Table 1 Socio-demographic characteristics of hypertensive elderly in Shandong, China, 2013

\begin{tabular}{|c|c|c|c|c|c|}
\hline Characteristics & Total $(n=2007)$ & Rural $(n=1107)$ & Urban $(n=900)$ & $x^{2}$ & $P$ \\
\hline$\overline{\text { Age }}$ & & & & 20.159 & $<0.001$ \\
\hline $65-69$ & $743(37.0)$ & $417(37.7)$ & $326(36.2)$ & & \\
\hline $70-74$ & $590(29.4)$ & $292(26.4)$ & 298(33.1) & & \\
\hline $75-79$ & 373(18.6) & $202(18.2)$ & $171(19.0)$ & & \\
\hline$\geq 80$ & $301(15.0)$ & 196(17.7) & 105(11.7) & & \\
\hline Gender & & & & 15.138 & $<0.001$ \\
\hline Male & $850(42.4)$ & $426(38.5)$ & $424(47.1)$ & & \\
\hline Female & 1157(57.6) & $681(61.5)$ & $476(52.9)$ & & \\
\hline Marital status & & & & 30.595 & $<0.001$ \\
\hline Single & $546(27.2)$ & $356(32.3)$ & $710(78.9)$ & & \\
\hline Married & $1461(72.8)$ & $751(67.8)$ & 190(21.1) & & \\
\hline Education level & & & & 421.712 & $<0.001$ \\
\hline No formal education & $702(35.0)$ & $561(50.7)$ & $141(15.7)$ & & \\
\hline Primary education & $656(32.7)$ & $386(34.9)$ & $270(30.0)$ & & \\
\hline Secondary or above & $649(32.3)$ & $160(14.5)$ & $489(54.3)$ & & \\
\hline Employment & & & & 319.858 & $<0.001$ \\
\hline Employed & $379(18.9)$ & $365(33.0)$ & 14(1.6) & & \\
\hline Unemployed & 1628(81.1) & $742(67.0)$ & 886(98.4) & & \\
\hline Personal income & & & & 749.689 & $<0.001$ \\
\hline $0 \sim 2500$ & 434(21.6) & 408(36.9) & $26(2.9)$ & & \\
\hline $2500 \sim 5000$ & $353(17.6)$ & 292(26.4) & $61(6.8)$ & & \\
\hline $5000 \sim 10,000$ & $456(22.7)$ & $245(22.1)$ & $211(23.4)$ & & \\
\hline $10,000 \sim 20,000$ & $457(22.8)$ & $127(11.5)$ & $330(36.7)$ & & \\
\hline$\geq 20,000$ & $307(15.3)$ & $35(3.2)$ & $272(30.2)$ & & \\
\hline Self-rated health & & & & 10.715 & 0.005 \\
\hline Bad & $708(35.3)$ & $420(37.9)$ & 288(32.0) & & \\
\hline Moderate & $905(45.1)$ & $493(44.5)$ & $412(45.8)$ & & \\
\hline Good & 394(19.6) & 194(17.5) & $200(22.2)$ & & \\
\hline Medication frequency & & & & 47.338 & $<0.001$ \\
\hline On time & 1587(79.1) & $813(73.4)$ & 774(86.0) & & \\
\hline Occasional & $321(16.0)$ & $224(20.2)$ & $97(10.8)$ & & \\
\hline Never & $99(4.9)$ & $70(6.3)$ & 29(3.2) & & \\
\hline Blood pressure level currently & & & & 46.105 & $<0.001$ \\
\hline Abnormal/unsure & $833(41.5)$ & $534(48.3)$ & 299(33.2) & & \\
\hline Normal & $1174(58.5)$ & $573(51.8)$ & $601(66.8)$ & & \\
\hline Accepting health care professionals' guidance & & & & 12.118 & $<0.001$ \\
\hline Yes & 1386(69.1) & $800(72.3)$ & $586(65.1)$ & & \\
\hline No & $620(30.9)$ & $306(27.7)$ & $314(34.9)$ & & \\
\hline Measurement frequency & & & & 173.933 & $<0.001$ \\
\hline Weekly & $955(47.6 \%)$ & $380(34.3 \%)$ & $575(63.9 \%)$ & & \\
\hline More than a week & $1052(52.42 \%)$ & $727(65.7 \%)$ & $325(36.1 \%)$ & & \\
\hline
\end{tabular}

Note: The italic entries mean that these results were statistically significant $(P<0.05)$ 
Table 2 Descriptive statistics for blood pressure measurement frequency

\begin{tabular}{llll}
\hline Measurement frequency & Rural (\%) & Urban (\%) & Total (\%) \\
\hline Weekly & $380(34.3)$ & $575(63.9)$ & $955(47.6)$ \\
Monthly & $445(40.2)$ & $232(25.8)$ & $677(33.7)$ \\
3 months & $184(16.6)$ & $49(5.4)$ & $233(11.6)$ \\
6 months & $47(4.2)$ & $24(2.7)$ & $71(3.5)$ \\
More than 6 months & $51(4.6)$ & $20(2.2)$ & $71(3.5)$ \\
Total & $1107(55.2)$ & $900(44.8)$ & 2007 \\
\hline
\end{tabular}

BP measurement among urban elderly. The results showed that individuals who had secondary or above education $(\mathrm{OR}=1.730,95 \% \mathrm{CI}=1.217-2.460)$ were significantly associated with more frequent BP measurement than those individuals who had no formal education. What is more, elderly who reported moderate self-rated health were less likely to measure BP on time than bad ones $(\mathrm{OR}=0.743,95 \% \mathrm{CI}=0.565-0.977)$. Those elderly hypertensive patients who took medicine occasionally (OR $=0.426,95 \% \mathrm{CI}=0.294-0.619)$ or never took medicine $(\mathrm{OR}=0.374,95 \% \mathrm{CI}=0.193-0.725)$ were less likely to practice BP measurement compared to those who took medicine on time. Besides, patients with normal BP currently were associated with more frequent $\mathrm{BP}$ measurement compared to those abnormal/unsure ones $(\mathrm{OR}=$ 1.484, 95\% CI =1.154-1.909). Patients who had not accepted health care professionals' guidance recently were less likely to engage in timely BP measurement compared to those who had $(\mathrm{OR}=0.643,95 \% \mathrm{CI}=0.500-0.827)$ (Table 5).

\section{Discussion}

In our study, $47.6 \%$ of elderly patients engaged in weekly or more BP measurement, which is similar with previous studies $[16-18,22]$. The data from the HealthStyles survey showed a $57 \%$ prevalence of regular use of BP measurement in 2008 for hypertensive adults 65 years of age and older, which was much higher than our results $[11,21]$.

Our data showed that the prevalence of weekly BP measurement in urban elderly was higher than that in rural elderly (63.9\% vs 34.3\%), and rural-urban difference was significant in BP measurement frequency after controlling age, gender, marital status, education level, income, self-rated health, and BP-related variables. The first reason is that the knowledge about prevention and treatment of hypertension among patients in rural areas were significantly lower than that in urban areas [23]. Most of the patients in rural areas knew less about the importance of BP measurement and how to measure BP accurately. Second, rural individuals were less likely to own a sphygmomanometer than their counterparts in urban areas [24]. Therefore, BP measurements are poorly accessible in rural areas. Third, the levels of awareness, treatment, and control of hypertension in rural areas were significantly lower than urban areas $[6,7]$. Several evidences have suggested that the percentage of participants engaged in weekly BP measurement significantly increased with being aware of, treated for, and controlled for hypertension $[25,26]$.

Extensive researches showed that BP measurement is the first step of hypertension management, and regular BP measurement contributes to hypertension prevention and control [27]. Our results showed that medication frequency and accepting health care professionals' guidance were significantly positively associated with BP measurement frequency among both rural and urban elderly. One possible reason may be that the elderly patients with regular medication may pay more attention to BP management and follow doctors' guidance strictly. These behaviors are very helpful to maintain regular BP measurement. In addition, health care professionals' guidance may contribute to more frequent engagement in BP measurement. Studies have indicated the importance of professionals' guidance on BP measurement $[26,28]$. Elderly hypertensive patients who had accepted health care professionals' guidance usually are told to engage in regularly BP measurement. This is much more helpful to assist patients to be aware of the importance of BP measurement.

Among rural elderly, personal income was significantly positively associated with the frequency of BP measurement. Many studies indicated that personal income was an important influencing factor associated with BP control in rural areas, which was in agreement with the finding of this study $[29,30]$. The explanation may be that the health service utilization of the low-income patients was lower than that of high-income ones [31]. Patients with high-income have more opportunities to accept the health care professionals' guidance on BP control and measure blood pressure while receiving the health care service. In that way, they may put more emphasis on $\mathrm{BP}$ measurement and measure BP more frequently.

In our study, those married elderly usually practice BP measurement more frequent than single ones in urban area. That may thanks to the reminding of their spouse. What is more, the elderly patients with higher education level engaged in more frequent $\mathrm{BP}$ measurement in urban areas. There might be three explanations for this finding. First, patients with high level of education make better use of home sphygmomanometers, which provide convenience for BP measurement [28]. Second, elderly with higher education level usually had higher level of health literacy [32, 33]. There were evidences proved that hypertensive with higher health literacy had better control of BP $[34,35]$. That is because that education offers individuals more opportunities to learn about health and health risks; thus, they more likely to choose 
Table 3 Factors associated with blood pressure measurement among the hypertensive elderly in Shandong, China, 2013

\begin{tabular}{|c|c|c|c|c|c|c|}
\hline & Model 1 & $P$ & Model 2 & $P$ & Model 3 & $P$ \\
\hline & OR $(95 \% \mathrm{Cl})$ & & OR $(95 \% \mathrm{Cl})$ & & OR $(95 \% \mathrm{Cl})$ & \\
\hline \multicolumn{7}{|l|}{ Residence } \\
\hline Urban & 1.0 & & 1.0 & & 1.0 & \\
\hline Rural & $0.292(0.250-0.341)$ & $<0.001$ & $0.459(0.376-0.562)$ & $<0.001$ & $0.467(0.380-0.575)$ & $<0.001$ \\
\hline \multicolumn{7}{|l|}{ Age } \\
\hline $65-69$ & & & 1.0 & & 1.0 & \\
\hline $70-74$ & & & $1.062(0.865-1.303)$ & 0.566 & $1.046(0.849-1.289)$ & 0.672 \\
\hline $75-79$ & & & $0.963(0.769-1.206)$ & 0.743 & $1.002(0.795-1.262)$ & 0.987 \\
\hline$\geq 80$ & & & $0.839(0.655-1.075)$ & 0.165 & $0.834(0.647-1.075)$ & 0.162 \\
\hline \multicolumn{7}{|l|}{ Gender } \\
\hline Male & & & 1.0 & & 1.0 & \\
\hline Female & & & $1.053(0.884-1.254)$ & 0.563 & $1.046(0.874-1.251)$ & 0.626 \\
\hline \multicolumn{7}{|l|}{ Marital status } \\
\hline Single & & & 1.0 & & 1.0 & \\
\hline Married & & & $1.187(0.977-1.441)$ & 0.084 & $1.236(1.013-1.508)$ & 0.037 \\
\hline \multicolumn{7}{|l|}{ Education level } \\
\hline No formal education & & & 1.0 & & 1.0 & \\
\hline Primary education & & & $1.098(0.892-1.352)$ & 0.376 & $1.135(0.917-1.405)$ & 0.244 \\
\hline Secondary or above & & & $1.397(1.093-1.786)$ & 0.008 & $1.485(1.154-1.911)$ & 0.002 \\
\hline \multicolumn{7}{|l|}{ Personal income (RMB) } \\
\hline $0 \sim 2500$ & & & 1.0 & & 1.0 & \\
\hline $2500 \sim 5000$ & & & $0.940(0.727-1.215)$ & 0.636 & 0.935(0.719-1.216) & 0.616 \\
\hline $5000 \sim 10,000$ & & & $1.290(1.005-1.655)$ & 0.045 & $1.274(0.987-1.644)$ & 0.063 \\
\hline $10,000 \sim 20,000$ & & & $1.742(1.331-2.279)$ & $<0.001$ & $1.589(1.206-2.093)$ & 0.001 \\
\hline$\geq 20,000$ & & & $1.779(1.304-2.428)$ & $<0.001$ & $1.621(1.179-2.229)$ & 0.003 \\
\hline \multicolumn{7}{|l|}{ Self-rated health } \\
\hline Bad & & & 1.0 & & 1.0 & \\
\hline Moderate & & & $0.965(0.808-1.152)$ & 0.691 & $0.877(0.730-1.053)$ & 0.159 \\
\hline Good & & & $0.973(0.778-1.217)$ & 0.812 & $0.883(0.702-1.111)$ & 0.289 \\
\hline \multicolumn{7}{|l|}{ Medication frequency } \\
\hline On time & & & & & 1.0 & \\
\hline Occasional & & & & & $0.503(0.400-0.633)$ & $<0.001$ \\
\hline Never & & & & & $0.371(0.243-0.566)$ & $<0.001$ \\
\hline \multicolumn{7}{|l|}{$\mathrm{BP}^{\mathrm{a}}$ level currently } \\
\hline Abnormal/unsure & & & & & 1.0 & \\
\hline Normal & & & & & $1.292(1.095-1.526)$ & 0.002 \\
\hline \multicolumn{7}{|c|}{ Accepting health care professionals' guidance } \\
\hline Yes & & & & & 1.0 & \\
\hline No & & & & & $0.579(0.484-0.693)$ & $<0.001$ \\
\hline
\end{tabular}

Note: The italic entries mean that these results were statistically significant $(P<0.05)$

$B P$ blood pressure

healthier lifestyle (such as measure BP timely) to prevent or manage diseases $[35,36]$. Third, elderly with lower education often face greater socioeconomic stress; therefore, they lack the financial assistance to support BP measurement [37]. Our study also found that hypertension patients with moderate self-rated health were associated with less frequent BP measurement compared to those bad ones. It is mainly because hypertensive whose 
Table 4 Factors associated with blood pressure measurement among rural elderly in Shandong, China, 2013

\begin{tabular}{|c|c|c|c|c|c|c|}
\hline & \multicolumn{2}{|c|}{ Measurement frequency } & \multicolumn{2}{|l|}{ Univariate model } & \multicolumn{2}{|l|}{ Adjusted } \\
\hline & 0 & 1 & OR $(95 \% \mathrm{Cl})$ & $P$ & OR $(95 \% \mathrm{Cl})$ & $P$ \\
\hline Age & & & & & $N A^{a}$ & \\
\hline $65-69$ & $260(62.4)$ & $157(37.6)$ & 1.0 & & & \\
\hline $70-74$ & $187(64.0)$ & $105(36.0)$ & $1.020(0.761-1.366)$ & 0.897 & & \\
\hline $75-79$ & $140(69.3)$ & $62(30.7)$ & $0.871(0.632-1.199)$ & 0.397 & & \\
\hline$\geq 80$ & $140(71.4)$ & $56(28.6)$ & $0.828(0.591-1.160)$ & 0.272 & & \\
\hline Gender & & & & & NA & \\
\hline Male & $279(65.5)$ & $147(34.5)$ & 1.0 & & & \\
\hline Female & $448(65.8)$ & $233(34.2)$ & $0.981(0.766-1.257)$ & 0.882 & & \\
\hline Marital status & & & & & NA & \\
\hline Single & $243(68.3)$ & $113(31.7)$ & 1.0 & & & \\
\hline Married & $484(64.4)$ & 267 (35.6) & $1.169(0.902-1.515)$ & 0.238 & & \\
\hline Education level & & & & & NA & \\
\hline No formal education & $383(68.3)$ & $178(31.7)$ & 1.0 & & & \\
\hline Primary education & $247(64.0)$ & $139(36.0)$ & 1.165(0.890-1.525) & 0.267 & & \\
\hline Secondary or above & $97(60.6)$ & $63(39.4)$ & $1.248(0.872-1.787)$ & 0.225 & & \\
\hline \multicolumn{7}{|l|}{ Personal income (RMB) } \\
\hline $0 \sim 2500$ & $282(69.1)$ & $126(30.9)$ & 1.0 & & 1.0 & \\
\hline $2500 \sim 5000$ & $206(70.5)$ & $86(29.5)$ & 0.953(0.716-1.267) & 0.739 & $0.951(0.717-1.261)$ & 0.726 \\
\hline $5000 \sim 10,000$ & $155(63.3)$ & $90(36.7)$ & $1.321(0.984-1.773)$ & 0.064 & $1.308(0.981-1.745)$ & 0.067 \\
\hline $10,000 \sim 20,000$ & $63(49.6)$ & $64(50.4)$ & $2.039(1.421-2.925)$ & $<0.001$ & $2.064(1.452-2.934)$ & $<0.001$ \\
\hline$\geq 20,000$ & $21(60.0)$ & $14(40.0)$ & $1.372(0.733-2.566)$ & 0.323 & $1.370(0.739-2.541)$ & 0.318 \\
\hline \multicolumn{7}{|l|}{ Self-rated health } \\
\hline Bad & $283(67.4)$ & $137(32.6)$ & 1.0 & & 1.0 & \\
\hline Moderate & $309(62.7)$ & $184(37.3)$ & $1.008(0.790-1.286)$ & 0.949 & $1.088(0.858-1.380)$ & 0.487 \\
\hline Good & $135(69.6)$ & $59(30.4)$ & $0.684(0.491-0.951)$ & 0.024 & $0.746(0.540-1.029)$ & 0.074 \\
\hline \multicolumn{7}{|l|}{ Medication frequency } \\
\hline On time & $494(60.8)$ & $319(39.2)$ & 1.0 & & 1.0 & \\
\hline Occasional & $174(77.7)$ & $50(22.3)$ & $0.544(0.408-0.727)$ & $<0.001$ & $0.539(0.404-0.718)$ & $<0.001$ \\
\hline Never & $59(84.3)$ & $11(15.7)$ & $0.361(0.207-0.630)$ & $<0.001$ & $0.349(0.201-0.604)$ & $<0.001$ \\
\hline BP level currently & & & & & NA & \\
\hline Abnormal/unsure & $370(69.3)$ & $164(30.7)$ & 1.0 & & & \\
\hline Normal & $357(62.3)$ & $216(37.7)$ & $1.183(0.947-1.478)$ & 0.139 & & \\
\hline \multicolumn{7}{|c|}{ Accepting health care professionals' guidance } \\
\hline Yes & $492(61.5)$ & $308(38.5)$ & 1.0 & & 1.0 & \\
\hline No & $235(76.8)$ & $71(23.2)$ & $0.513(0.394-0.669)$ & $<0.001$ & $0.519(0.400-0.674)$ & $<0.001$ \\
\hline
\end{tabular}

Note: The italic entries mean that these results were statistically significant $(P<0.05)$

$N A$ not applicable

$B P$ blood pressure

symptoms were less severe often neglects to take precautions on BP management.

The findings in this report are subject to some limitations. First, the cross-sectional nature of our survey precludes us from assigning cause and effect to our results. Second, the analyses were depended on self-reports, which involves a risk of information bias due to false or inaccurate responses from participants. Third, there is a limitation with assumptions made in converting reported "the last time measure BP" into BP measurement frequency. For example, it is conceivable that a person may measure $\mathrm{BP}$ within a week occasionally; however, according to our 
Table 5 Binary logistic regression analysis on the risk factors and measurement frequency among urban elderly $(n=1107)$

\begin{tabular}{|c|c|c|c|c|c|c|}
\hline & \multicolumn{2}{|c|}{ Measurement frequency } & \multicolumn{2}{|l|}{ Univariate model } & \multicolumn{2}{|l|}{ Adjusted model } \\
\hline & 0 & 1 & $95 \% \mathrm{Cl}$ & $P$ & $95 \% \mathrm{Cl}$ & $P$ \\
\hline Age & & & & & NA & \\
\hline $65-69$ & $118(36.2)$ & $208(63.8)$ & 1.0 & & & \\
\hline $70-74$ & $101(33.9)$ & $197(66.1)$ & $1.128(0.833-1.528)$ & 0.436 & & \\
\hline $75-79$ & $61(35.7)$ & $110(64.3)$ & $1.171(0.830-1.650)$ & 0.368 & & \\
\hline$\geq 80$ & $45(42.9)$ & $60(57.1)$ & $0.888(0.598-1.319)$ & 0.557 & & \\
\hline Gender & & & & & NA & \\
\hline Male & $148(34.9)$ & $276(65.1)$ & 1.0 & & & \\
\hline Female & $177(37.2)$ & $299(62.8)$ & $1.157(0.886-1.511)$ & 0.284 & & \\
\hline \multicolumn{7}{|l|}{ Marital status } \\
\hline Single & $84(44.2)$ & $106(55.8)$ & 1.0 & & 1.0 & \\
\hline Married & $241(33.9)$ & $469(66.1)$ & $1.406(1.024-1.931)$ & 0.035 & $1.367(1.017-1.837)$ & 0.038 \\
\hline \multicolumn{7}{|l|}{ Education level } \\
\hline No formal education & $65(46.1)$ & $76(53.9)$ & 1.0 & & 1.0 & \\
\hline Primary education & $106(39.3)$ & $164(60.7)$ & $1.137(0.780-1.657)$ & 0.505 & 1.144(0.797-1.644) & 0.466 \\
\hline secondary or above & $154(31.5)$ & $335(68.5)$ & $1.714(1.157-2.539)$ & 0.007 & $1.730(1.217-2.460)$ & 0.002 \\
\hline Personal income (RMB) & & & & & NA & \\
\hline $0 \sim 2500$ & $10(38.5)$ & $16(61.5)$ & 1.0 & & & \\
\hline $2500 \sim 5000$ & $29(47.5)$ & $32(52.5)$ & $0.614(0.267-1.415)$ & 0.252 & & \\
\hline $5000 \sim 10,000$ & $85(40.3)$ & $126(59.7)$ & $0.731(0.345-1.547)$ & 0.412 & & \\
\hline $10,000 \sim 20,000$ & $114(34.5)$ & $216(65.5)$ & $0.828(0.393-1.742)$ & 0.618 & & \\
\hline$\geq 20,000$ & $87(32.0)$ & $185(68.0)$ & $0.921(0.433-0.297)$ & 0.831 & & \\
\hline \multicolumn{7}{|l|}{ Self-rated health } \\
\hline $\mathrm{Bad}$ & $105(36.5)$ & $183(63.5)$ & 1.0 & & 1.0 & \\
\hline Moderate & $158(38.3)$ & $254(61.7)$ & $0.727(0.549-0.963)$ & 0.026 & $0.743(0.565-0.977)$ & 0.034 \\
\hline Good & $62(31.0)$ & $138(69.0)$ & 1.093(0.774-1.544) & 0.614 & $1.121(0.799-1.572)$ & 0.509 \\
\hline \multicolumn{7}{|l|}{ Medication frequency } \\
\hline On time & $252(32.6)$ & $522(67.4)$ & 1.0 & & 1.0 & \\
\hline Occasional & $55(56.7)$ & $42(43.3)$ & $0.433(0.297-0.631)$ & $<0.001$ & $0.426(0.294-0.619)$ & $<0.001$ \\
\hline Never & $18(62.1)$ & $11(37.9)$ & $0.378(0.195-0.735)$ & 0.004 & $0.374(0.193-0.725)$ & 0.004 \\
\hline \multicolumn{7}{|c|}{ Blood pressure level currently } \\
\hline Abnormal/unsure & $194(32.3)$ & $407(67.7)$ & 1.0 & & 1.0 & \\
\hline Normal & $131(43.8)$ & $168(56.2)$ & $1.474(1.143-1.901)$ & 0.003 & 1.484(1.154-1.909) & 0.002 \\
\hline \multicolumn{7}{|c|}{ Accepting health care professionals' guidance } \\
\hline Yes & $188(32.1)$ & $398(67.9)$ & 1.0 & & 1.0 & \\
\hline No & $137(43.6)$ & $177(56.4)$ & $0.635(0.493-0.819)$ & $<0.001$ & $0.643(0.500-0.827)$ & 0.001 \\
\hline
\end{tabular}

Note: The italic entries mean that these results were statistically significant $(P<0.05)$ NA not applicable

definition, the person will be classified as engaging in BP measurement weekly. Fortunately, this situation is not common and its impact on the result is not obvious.

\section{Conclusion}

In conclusion, this study found that the elderly in urban areas performed BP measurement more frequent than the elderly in rural areas. In general, personal income, medication frequency, and accepting health care professionals' guidance were associated factors of BP measurement frequency among rural elderly. Marital status, education level, self-rated health, medication frequency, BP level currently, and accepting health care professionals' guidance were associated with the BP measurement frequency among urban 
elderly. The results of this analysis highlight the ruralurban difference in the use of BP measurement and the necessary to better understand the factors associated with more frequent BP measurement. Therefore, more work will be needed for $\mathrm{BP}$ measurement to prevent its consequences in rural areas of China. First, the government should develop targeting health promotion policies to improve health literacy among the elderly. Second, the communities should pay close attention to those identified at-risk subgroups to increase the BP measurement frequency among the elderly.

\section{Abbreviations}

BP: Blood pressure; NA: Not applicable; OR: Odds ratio

\section{Acknowledgements}

We would like to thank the Center for Health Economics Experiment and Public Policy, School of Public Health, Shandong University.

\section{Funding}

This work was supported by two grants of National Natural Science Foundation of China (grant numbers 71673169 and 71673170).

\section{Availability of data and materials}

Please contact author for data requests.

\section{Authors' contributions}

$L X$ and $C Z$ conceived the idea. $L S$ and $J$ participated in the statistical analysis and interpretation of the results. QW drafted the manuscript. JZhang, JZhu, SX, and ZY gave many valuable comments on the draft and also polished it. All authors read and approved the final manuscript.

\section{Ethics approval and consent to participate}

The institutional review board of the Chinese National Bureau of Statistics provided review and ethics approval of the survey (license number 2013(71)). All respondents were read a statement that explained the purpose of the survey and gave consent to continue.

\section{Consent for publication}

Consent for publication was obtained from the participants.

\section{Competing interests}

The authors declare that they have no competing interests.

\section{Publisher's Note}

Springer Nature remains neutral with regard to jurisdictional claims in published maps and institutional affiliations.

Received: 25 January 2018 Accepted: 6 November 2018

\section{Published online: 22 November 2018}

\section{References}

1. Ezzati M, Lopez AD, Rodgers A, Vander Hoorn S, Murray CJ. Comparative risk assessment collaborating group. Selected major risk factors and global and regional burden of disease. Lancet. 2002;360(9343):1347-60.

2. NCD Risk Factor Collaboration. (NCD-RisC). Worldwide trends in blood pressure from 1975 to 2015: a pooled analysis of 1479 populationbased measurement studies with 19.1 million participants. Lancet. 2017; 389(10064):37-55

3. Q\&As on Hypertension http://www.who.int/features/qa/82/en/

4. He J, Gu D, Chen J, Wu X, Kelly TN, Huang J-f, Chen J-c, Chen C-S, Bazzano LA, Reynolds K, Whelton PK, Klag MJ. Premature deaths attributable to blood pressure in China: a prospective cohort study. Lancet. 2009;374(9703): 1765-72.

5. Lu J, Lu Y, Wang X, et al. Prevalence, awareness, treatment, and control of hypertension in China: data from 1.7 million adults in a population-based screening study (China PEACE million persons project). Lancet. 2017; 390(10112):2549-58.
6. World Health Day 2013: measure your Blood Press, reduce your risk. http://www. who.int/mediacentre/news/releases/2013/world_health_day_20130403/en/

7. Xiao HY. Analysis of the effect of blood pressure self testing approach in managing the elderly with hypertension in the community China. Contin Med Educ. 2015;7(22):177-8.

8. Li R, Luo LM. Effect of self-test blood pressure in community management of elderly hypertensive patients. Chin J Evid Based Cardiovasc Med. 2015; 7(4):484-6.

9. Cappuccio FP, Kerry SM, Forbes L, Donald A. Blood pressure control by home monitoring: meta-analysis of randomised trials. BMJ. 2004;329(7458):145.

10. Fletcher BR, Hartmann-Boyce J, Hinton L, McManus RJ. The effect of self-monitoring of blood pressure on medication adherence and lifestyle factors: a systematic review and meta-analysis. Am J Hypertens. 2015;28(10):1209-21.

11. Ogedegbe $G$, Schoenthaler A. A systematic review of the effects of home blood pressure monitoring on medication adherence. J Clin Hypertens (Greenwich). 2006:8(3):174-80.

12. Cuspidi C, Meani S, Lonati L, Fusi V, Magnaghi G, Garavelli G, Palumbo G, Pini C, Vaccarella A, Parati G, Leonetti G, Zanchetti A. Lombardy regiona section of the Italian hypertension society. Prevalence of home blood pressure measurement among selected hypertensive patients: results of a multicenter survey from six hospital outpatient hypertension clinics in Italy. Blood Press. 2005;14(4):251-6.

13. Feng GF, Yuan H, Xie ZQ, Xu JJ, Sun NN, Chen YY, Lin ZQ. Home blood pressure monitoring in elderly hypertensive patients. Chin J Geriatr Heart Brain Verssel Dis. 2017;19(6):584-7.

14. Yang XH, Yao $\mathrm{CH}$. Relationship between home BP measurement rate in hypertensive outpatients receiving community service and BP control in Beijing. Chin J Hypertens. 2010;18(8):739-43.

15. Wang Y, Wang S, Wan SX, Wang MM, Zhong GY, Zhou YF, Pan P. Home blood pressure monitoring in hypertensive patients in communities of Wuhou strict, Chengdu city. Chin J Hypertens. 2014;22(2):142-5.

16. He W, Goodkind D, Kowal P. An Aging World. In: International Population Reports; 2015. http://age-pride.org/wordpress/wp-content/ uploads/2016/04/Global-aging-and-minority-populations-Healthcareaccess-quality-of-care-and-use-of-services.pdf.

17. Guo J, Yu C, Lyu J, Guo Y, Bian Z, Zhou H, Tan Y, Pei P, Chen J, Chen Z, Li L. China Kadoorie biobank (CKB) collaborative group. Status of prevalence, awareness, treatment and controll on hypertension among adults in 10 regions, China. Zhonghua Liu Xing Bing Xue Za Zhi. 2016;37(4):469-74.

18. Zilong L, Junli T, Gaohui Z, Jiyu Z, Zhentao F, Chunxiao X, Congcong G, Xiaolei G. Prevalence, awareness, treatment and control of hypertension in adults in Shandong province, 2013. Zhonghua Liu Xing Bing Xue Za Zhi. 2016;37(9):1207-12.

19. Xu Y, Gao J, Zhou Z, Xue Q, Yang J, Luo H, Li Y, Lai S, Chen G. Measurement and explanation of socioeconomic inequality in catastrophic health care expenditure: evidence from the rural areas of Shaanxi Province. BMC Health Serv Res. 2015;15(1):256.

20. Meng Q, Xu L, Zhang Y, Qian J, Cai M, Xin Y, Gao J, Xu K, Boerma JT, Barber SL. Trends in access to health services and financial protection in China between 2003 and 2011: a cross-sectional study. Lancet. 2012; 379(9818):805-14

21. Wang Y, Wang YJ, Gu H, Qain Y, Zhang J, Tang X, Sun J, Zhu D. Use of home blood pressure monitoring among hypertensive adults in primary care Minhang community survey. Blood Press Monit. 2014;19(3):4.

22. Liu LS. Writing group of 2010 Chinese guidelines for the Management of Hypertension. 2010 Chinese guidelines for the management of hypertension. Zhonghua Xin Xue Guan Bing Za Zhi. 2011;39(7):579-615.

23. Wang X, Bai HF, Ma KM, Li B, Qi JH, Chen BJ, An N, Chen H, Duan XY, Sui H, Yu XW, Liu RK, Zuo HJ, Liu J, Wu YF. Relationship between the patients' knowledge on hypertension prevention and control and the rate on BP control. Zhonghua Liu Xing Bing Xue Za Zhi. 2003;24(12):1082-5.

24. Li YQ, Cao Y, Liu XR. Status quo of home-equipped sphygmomanometers and their application in Beijing. Chin Gen Pract. 2014;17(32):3.

25. Ostchega Y, Berman L, Hughes JP, Chen TC, Chiappa MM. Home blood pressure monitoring and hypertension status among US adults: the National Health and nutrition examination survey (NHANES), 2009-2010. Am J Hypertens. 2013;26(9):1086-92.

26. Ostchega Y, Zhang G, Kit BK, Nwankwo T. Factors associated with home blood pressure monitoring among US adults: National Health and nutrition examination survey, 2011-2014. Am J Hypertens. 2017;30(11):1126-32. 
27. Self-Measured BP Monitoring: Comparative Effectiveness. <https:// effectivehealthcare.ahrq.gov/topics/measuring-blood-pressure/research/>.

28. Zahid H, Amin A, Amin E, Waheed S, Asad A, Faheem A, Jawaid S, Afzal A, Misbah S, Prevalence MK. Predictors of use of home sphygmomanometers among hypertensive patients. Cureus. 2017;9(4):e1155.

29. Zeng XY, Zhang M, Li YC, Huang ZJ, Wang LM. Study on effects of community-based management of hypertension patients aged $\geq 35$ years and influencing factors in urban and rural areas of China, 2010. Zhonghua Liu Xing Bing Xue Za Zhi. 2016;37(5):612-7.

30. Li L, Li X, Kong HQ, Liu YC, Yang HX, Cai L. Prevalence, control and selfmanagement of hypertension among elderly residents in rural areas of Yunnan province. Chin J Public Health. 2018;34(5):690-2.

31. Jing SS, Yin AT, Meng QY, Liu XY, Yan F, Yu BR. Study on the equity of the health service utilization of rural chronic patients. Chin Health Econ. 2010; 29(2):35-7.

32. Huang WD, Sun PH. Analysis of related factors influencing health literacy of the elderly. Chin J Gerontol. 2010;30:1564-5.

33. Paasche-Orlow MK, Parker RM, Gazmararian JA, Nielsen-Bohlman LT, Rudd RR. The prevalence of limited health literacy. J Gen Intern Med. 2005;20(2): 175-84.

34. Pandit AU, Tang JW, Bailey SC, Davis TC, Bocchini MV, Persell SD, Wolf MS Education, literacy, and health: mediating effects on hypertension knowledge and control. Patient Educ Couns. 2009;75(3):381-5.

35. Shi D, Li J, Wang Y, Wang S, Liu K, Shi R, Zhang Q, Chen X. Association between health literacy and hypertension management in a Chinese community: a retrospective cohort study. Intern Emerg Med (e-pub ahead of print 16 Mar 2017. https://doi.org/10.1007/s11739-017-1651-7.

36. Understanding the Relationship Between Education and Health. (2014). https://nam.edu/wp-content/uploads/2015/06/BPHUnderstandingTheRelationship1.pdf. Accessed 30 Mar 2017

37. Akpolat T, Erdem Y, Derici U, Erturk S, Caglar S, Hasanoglu E, Karatan O, Sindel S, Turgan C. Use of home sphygmomanometers in Turkey: a nationwide survey. Hypertens Res. 2012;35(3):356-61.

Ready to submit your research? Choose BMC and benefit from:

- fast, convenient online submission

- thorough peer review by experienced researchers in your field

- rapid publication on acceptance

- support for research data, including large and complex data types

- gold Open Access which fosters wider collaboration and increased citations

- maximum visibility for your research: over $100 \mathrm{M}$ website views per year

At $\mathrm{BMC}$, research is always in progress.

Learn more biomedcentral.com/submissions 